\title{
Low temperature synthesis of $\mathrm{NiO} / \mathrm{Co}_{3} \mathrm{O}_{4}$ composite nanosheets as high performance Li-ion battery anode materials
}

\author{
LIANG QingQin $^{1}$, LI YueMing ${ }^{2} \&$ LI JingHong ${ }^{1 *}$ \\ ${ }^{1}$ Department of Chemistry, Tsinghua University, Beijing 100084, China; \\ ${ }^{2}$ State Key Laboratory of Metastable Materials Science and Technology, Yanshan University, Qinhuangdao 066004, China
}

Received October 27, 2011; accepted March 5, 2012; published online June 17, 2012

\begin{abstract}
$\mathrm{NiO} / \mathrm{Co}_{3} \mathrm{O}_{4}$ composite nanosheets have been synthesized via a facile method at low temperature for the first time. The as prepared materials were characterized by X-ray powder diffraction (XRD) and transmission electron microscopy (TEM), and the performance of Li-ion batteries (LIBs) as anode materials were also studied. By controlling the atom ratio of Ni:Co, not only the size of the nanosheets can be controlled, the electrode's conductivity and stability could also be greatly improved. The composite material showed a stable capacity retention during cycling ( $87 \%$ of the second capacity was retained after 15 cycles) even at a relatively large current rate $(400 \mathrm{~mA} / \mathrm{g})$. The $\mathrm{NiO} / \mathrm{Co}_{3} \mathrm{O}_{4}$ nanosheet might be promising candidate anode materials in high performance Li-ion batteries.
\end{abstract}

nanosheets, $\mathrm{NiO} / \mathrm{Co}_{3} \mathrm{O}_{4}$ composites, Li-ion batteries, anode

Citation: $\quad$ Liang Q Q, Li Y M, Li J H. Low temperature synthesis of $\mathrm{NiO} / \mathrm{Co}_{3} \mathrm{O}_{4}$ composite nanosheets as high performance Li-ion battery anode materials. Chin Sci Bull, 2012, 57: 4195-4198, doi: 10.1007/s11434-012-5290-0

Transition metal oxide materials have been widely used in catalysts, gas sensors, electrochromic devices, etc. [1-4], and it was proved that many transition metal oxides could also be used as anode materials for lithium ion batteries (LIBs). Compared with commercially graphite anode, these materials possessed much higher theoretical specific capacity [5]. However, there are still many challenges for the practical use of transition metal oxide materials in LIBs, such as the large expansion in volume, the serious aggregation or pulverization of active particles during charge-discharge, and their poor conductivity [6]. Many efforts have been tried to solve these problems, such as controlling the morphologies of materials, doping ions and coating carbon materials [7-12], all of these are trying to improve the structure stability or conductivity.

Among these transition metal oxides, $\mathrm{Co}_{3} \mathrm{O}_{4}$ has been demonstrated to be one of the most promising electrode materials for LIBs due to its high theoretical specific capacity

*Corresponding author (email: jhli@mail.tsinghua.edu.cn)
(890 mAh/g) [13]. However, cobalt is toxic and expensive, so one of the worthwhile efforts is to partially replace the $\mathrm{Co}$ in $\mathrm{Co}_{3} \mathrm{O}_{4}$ by $\mathrm{Ni}, \mathrm{Zn}, \mathrm{Cu}$, etc., because they are cheaper, eco-friendly and electrochemically active for $\mathrm{Li}$ insertion and extraction [14]. In addition, the cycle performance of $\mathrm{Co}_{3} \mathrm{O}_{4}$ as anode materials for LIBs is usually poor. As is known, the morphology of electrode materials played an important role in determining the performance of LIBs. In recent years, nanosheet materials have attracted much interest in energy storage and conversion field due to their special properties $[15,16]$. They are very attractive as lithium storage materials because the crystallographic transformation of these materials can minimize the volume change during cycling and the large surface area and offer more active cites for the accommodation of lithium ions [17]. In this paper, we designed $\mathrm{NiO} / \mathrm{Co}_{3} \mathrm{O}_{4}$ composite nanosheets via a facile method to reduce the cobalt usage and improve its stability and conductivity. The electrochemical experiments were carried out and the result proved that the composites with larger nanosheets demonstrated greatly improved 
cycle performance.

\section{Materials and method}

\subsection{Reagents}

$\mathrm{Co}\left(\mathrm{NO}_{3}\right)_{2} \cdot 6 \mathrm{H}_{2} \mathrm{O}\left(98 \%\right.$, Beijing Chemical Co. Ltd.), $\mathrm{Ni}\left(\mathrm{NO}_{3}\right)_{2}$. $6 \mathrm{H}_{2} \mathrm{O}$ (98\%, Beijing Chemical Co. Ltd.), HTM (98\%, Sinapharm Group Co. Ltd.) and $\mathrm{H}_{2} \mathrm{O}_{2}(30 \mathrm{wt} \%$ solution in water, Sinapharm Group Co. Ltd.) were used as received.

\subsection{Preparation of $\mathrm{NiO} / \mathrm{Co}_{3} \mathrm{O}_{4}$ composite nanosheets}

The procedures of $\mathrm{Co}_{3} \mathrm{O}_{4}$ nanosheet's synthesis is: 0.01 $\mathrm{mol} / \mathrm{L} \mathrm{Co}\left(\mathrm{NO}_{3}\right)_{2} \cdot 6 \mathrm{H}_{2} \mathrm{O}$ was dissolved in $50 \mathrm{~mL}$ demonized water to form the solution A. Then 5 mmol HMT dissolved in $50 \mathrm{~mL}$ deionized water to form the solution $\mathrm{B}$, both of solution A and B were stirred separately for $30 \mathrm{~min}$ at room temperature then subsequently mixed together and stirred for another $30 \mathrm{~min}$, after that, $0.5 \mathrm{~mL}(30 \mathrm{wt} \%) \mathrm{H}_{2} \mathrm{O}_{2}$ was added drop by drop for $30 \mathrm{~min}$. Then the mixture was transferred to an oil bath reactor and stirred at $80^{\circ} \mathrm{C}$ for $3 \mathrm{~h}$, the black precipitate from the reactor were centrifuged, washed several times with demonized water and ethanol, and dried at $80^{\circ} \mathrm{C}$ overnight. The $\mathrm{NiO} / \mathrm{Co}_{3} \mathrm{O}_{4}$ composite nanosheets' syntheses were almost in the same procedure except the formation of solution A. To form these composites some $\mathrm{Ni}\left(\mathrm{NO}_{3}\right)_{2} \cdot 6 \mathrm{H}_{2} \mathrm{O}$ were added and the total metal ions amounts were still controlled at $0.01 \mathrm{~mol} / \mathrm{L}$. Two different $\mathrm{Co}^{2+} / \mathrm{Ni}^{2+}$ mole ratios $(3: 1 ; 2: 1)$ condition were used, and the result was defined as $\mathrm{NiO} / \mathrm{Co}_{3} \mathrm{O}_{4}$ composite nanosheet1 (NCCS-1), $\mathrm{NiO} / \mathrm{Co}_{3} \mathrm{O}_{4}$ composite nanosheet-2 (NCCS-2), respectively. All the samples were annealed at $400^{\circ} \mathrm{C}$ for $2 \mathrm{~h}$ before electrochemical measurements.

\subsection{Characterization}

$\mathrm{X}$-ray power diffraction (XRD) was performed on a Bruker D8-Advance X-ray powder diffractometer with monochromatized $\mathrm{CuK} \alpha$ radiation $(\lambda=1.5406 \AA)$. The scattering angles $(2 \theta)$ used in the measurements was from 10 to $80^{\circ}$. The morphology of the prepared samples was observed through transmission electron microscope (TEM) performed on $\mathrm{H}-7650 \mathrm{~B}$ at an accelerating voltage of $100 \mathrm{kV}$.

\subsection{Electrochemical measurements}

Electrochemical measurements were carried out using twoelectrode Swagelok type cells with lithium metal as the counter electrode and reference electrode. The electrode pellet was fabricated by pressing a mixture of $80 \mathrm{wt} \%$ active materials, $10 \mathrm{wt} \%$ acetylene black, and $10 \mathrm{wt} \%$ poly (vinylidene fluoride) (PVDF) onto a copper foil. The pellet and the Li metal were held apart with Celgard 2402 separator. The electrolyte solution was $1 \mathrm{~mol} / \mathrm{L} \mathrm{LiPF}_{6}$ dissolved in a mixture of ethylene carbonate (EC) and dimethyl carbonate $(\mathrm{DMC})$, in a volume ratio of $\mathrm{EC} / \mathrm{DMC}=1: 1$. Capacity cycle performances were recorded between 3.0 and $0.1 \mathrm{~V}$ at a current density of $400 \mathrm{~mA} / \mathrm{g}$, using a Land CT2001A test system (Wuhan, China). Electrochemical impedance measurements were carried out on a PARSTAT 2273 Potentiostat/galvanostat (Princeton applied research, USA) by applying an $\mathrm{AC}$ voltage of $5 \mathrm{mV}$ amplitude in the frequency range of $100 \mathrm{kHz}$ to $100 \mathrm{mHz}$. All measurements were carried out at room temperature.

\section{Results and discussion}

As seen from Figure 1, most of the peaks can be readily indexed to a spinel-type oxide $\mathrm{Co}_{3} \mathrm{O}_{4}$ (JCPDS card No. 421467, cubic, space group: Fd3m, $a=8.084 \AA$ ), After adding the Ni content, some of the NiO peaks such as (220) appeared (JCPDS card No. 01-1239). According to calculation using the Rietveld method, the weight ratio of $\mathrm{NiO}: \mathrm{Co}_{3} \mathrm{O}_{4}$ for NCCS-1 and NCCS-2 were 36:64, 47:53, respectively. It is also found that XRD peaks broaden and slightly shift toward a lower diffraction angle after adding Ni contents, indicating that crystallinity of materials gets worse. The lattice constant $\mathrm{Co}_{3} \mathrm{O}_{4}$ is $8.06 \AA$, while those of NCCS-1 and NCCS-2 are 8.09 and $8.11 \AA$, respectively, which suggests that lattices expanded after introduction of Ni. This should be caused by partial substitution of Co ions by $\mathrm{Ni}$ ion due to the similar properties of $\mathrm{Ni}$ and $\mathrm{Co}$.

Figure 2(a) shows the TEM images of as prepared pure $\mathrm{Co}_{3} \mathrm{O}_{4}$ nanosheets. With the increasing of $\mathrm{NiO}$ content, the diameters of nanosheets become larger (Figure 2(b),(c)), from several up to hundreds nanometers. The thicknesses for all these samples are less than $10 \mathrm{~nm}$, and thin nanostructure is favorable to electrochemical performance. It is also found that the nanosheets become wrinkle-like folded paper sheets with the increase of the size [18].

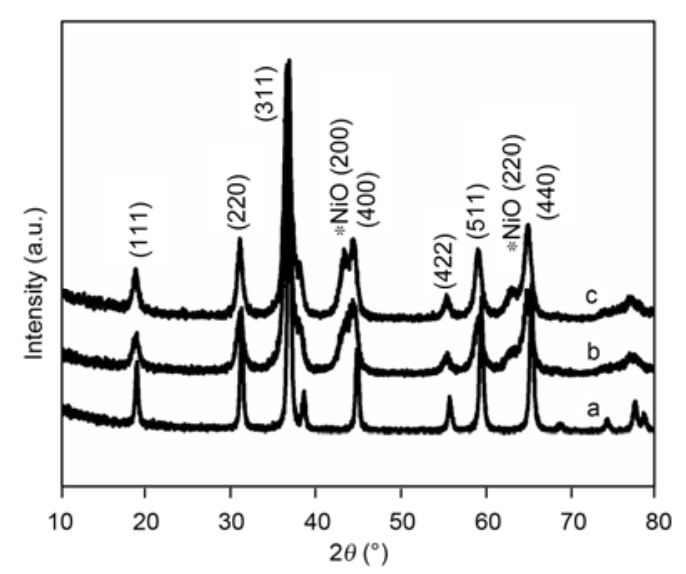

Figure 1 XRD patterns of the $\mathrm{Co}_{3} \mathrm{O}_{4}$ nanosheets (a), NCCS-1 (b) and NCCS-2 (c). 


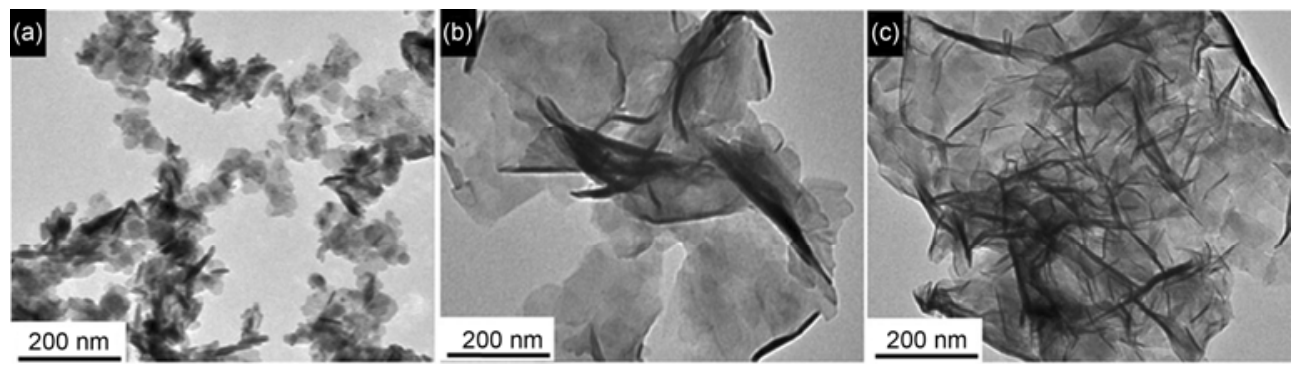

Figure 2 TEM images of the $\mathrm{Co}_{3} \mathrm{O}_{4}$ nanosheets (a), NCCS-1 (b) and NCCS-2 (c).

The cycle performance (Figure 3) clearly showed that after $\mathrm{Ni}$ doping, the capacity of the anode material could retained steadily. When the reaction proportion of $\mathrm{Ni}$ and Co added up to $1: 2$ (NCCS-2), the material showed a stable capacity retention during cycling (87\% of the second capacity was retained after 15 cycles), considering the inherent irreversible reaction such as the formation of SEI, that was a very good result for this kind of materials. The enhanced cycle performance might be due to composition with $\mathrm{NiO}$ and the lager particle size. Furthermore, transition metal like $\mathrm{Ni}$ has the catalytic activity to facilitate $\mathrm{Li}_{2} \mathrm{O}$ decomposition and help the electrode reaction $4 \mathrm{Li}_{2} \mathrm{O}+3 \mathrm{Co} \rightarrow 8 \mathrm{Li}+\mathrm{Co}_{3} \mathrm{O}_{4}$ to go easily [19], leading improved cycle performance.

The AC impedance spectra of the synthesized materials are shown in Figure 4. As shown in the curves, both of the impedance spectra consist of one semicircle in the high frequency region and an inclined straight line in the low frequency. The semicircle in the high frequency region is attributed to the charge-transfer resistance $\left(R_{\mathrm{ct}}\right)$, related to the charge transfer through the electrode/electrolyte interface. The inclined line corresponds to solid-state diffusion of lithium-ion (Warburg impedance) in the electrode materials. The intercept at $Z_{\mathrm{re}}$ in high frequency region was related to the resistance of the electrolytes $\left(R_{\mathrm{s}}\right)$. The two electrodes' impedance spectra can be analyzed by the equivalent circuit

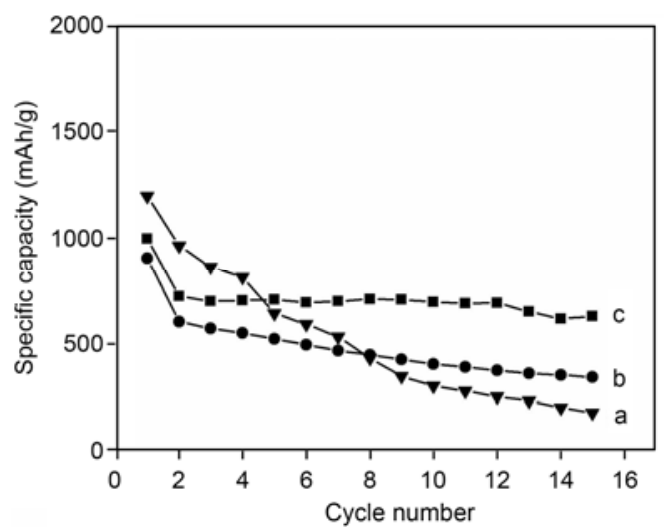

Figure 3 Capacity versus cycle number plot for $\mathrm{Co}_{3} \mathrm{O}_{4}$ nanosheets (a), NCCS-1 (b) and NCCS-2 (c) in the voltage range 0.1-3.0 V at current rate, $400 \mathrm{~mA} / \mathrm{g}$.

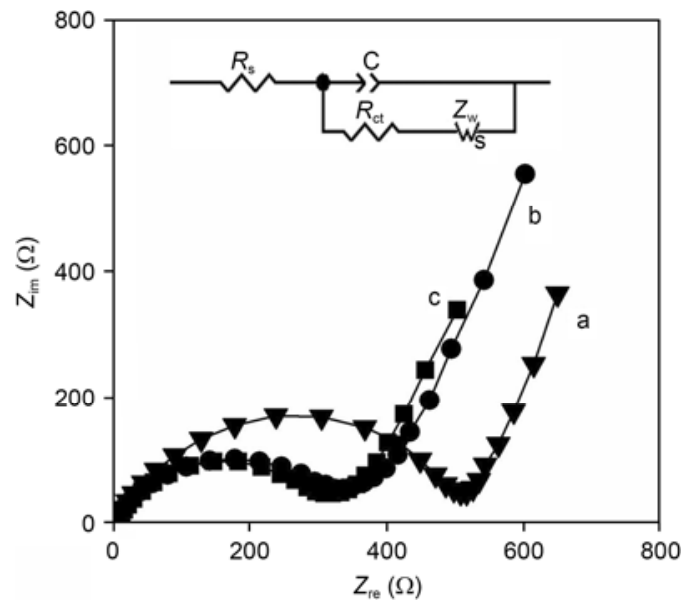

Figure 4 Nyquist plots of the $\mathrm{Co}_{3} \mathrm{O}_{4}$ nanosheets (a), NCCS-1 (b) and NCCS-2 (c). Voltage perturbation amplitude: $5 \mathrm{mV}$, frequency range: 100 $\mathrm{kHz}$ to $100 \mathrm{mHz}$ (inset: equivalent circuit mode plot; $R_{\mathrm{s}}$, resistance of the electrolytes; $R_{\mathrm{ct}}$, charge-transfer resistance; $Z_{\mathrm{w}}$, Warburg resistance; C, constant phase element).

mode in inset of Figure 4. A constant phase element (C) was used to instead of capacitance caused by the double layer. As seen from the Nyquist plot, charge-transfer resistance decreased sharply for the $\mathrm{NiO} / \mathrm{Co}_{3} \mathrm{O}_{4}$ composites compared with that of pure $\mathrm{Co}_{3} \mathrm{O}_{4}$ nanosheets. The decreased resistance might be attributed to the larger $2 \mathrm{D}$ nanosheets structure, $\mathrm{Ni}$ doping and composition with $\mathrm{NiO}$ [20-22].

\section{Conclusions}

In summary, we have succeeded in developing a simple method to synthesize $\mathrm{NiO} / \mathrm{Co}_{3} \mathrm{O}_{4}$ nanosheets at low temperature. It is found that the size of $\mathrm{NiO} / \mathrm{Co}_{3} \mathrm{O}_{4}$ composites nanosheets can be controlled via adjusting the ratio of reagents within a certain range. And the electrochemical results indicated that $\mathrm{NiO} / \mathrm{Co}_{3} \mathrm{O}_{4}$ composites nanosheets had improved cycle performance and the increased conductivity as anode materials for LIBs, compared with those of the $\mathrm{Co}_{3} \mathrm{O}_{4}$ nanosheets materials. The $\mathrm{NiO} / \mathrm{Co}_{3} \mathrm{O}_{4}$ composite nanosheets may be promising candidate anode materials for high performance Li-ion batteries. 
This work was supported by the National Natural Science Foundation of China (11079002), the National Basic Research Program of China (2011CB935700) and the Research Fund of Ministry of Education of China (20110002130007).

$1 \mathrm{Li} \mathrm{W} \mathrm{Y,} \mathrm{Xu} \mathrm{L} \mathrm{N}$, Chen J. $\mathrm{Co}_{3} \mathrm{O}_{4}$ nanomaterials in lithium-ion batteries and gas sensors. Adv Func Mater, 2005, 15: 851-857

2 Maruyama T, Arai S. Electrochromic properties of cobalt oxide thin films prepared by chemical vapor deposition. J Electrochem Soc, 1996, 143: 1383-1386

$3 \mathrm{Hu} \mathrm{L} \mathrm{H}$, Peng Q, Li Y D. Selective synthesis of $\mathrm{Co}_{3} \mathrm{O}_{4}$ nanocrystal with different shape and crystal plane effect on catalytic property for methane combustion. J Am Chem Soc, 2008, 130: 16136-16137

4 Barbero C, Planes G A, Miras M C. Redox coupled ion exchange in cobalt oxide films. Electrochem Commun, 2001, 3: 113-116

5 Poizot P, Laruelle S, Grugeon S, et al. Nano-sized transition-metal oxides as negative-electrode materials for lithium-ion batteries. Nature, 2000, 407: 496-499

6 Huang $\mathrm{X} \mathrm{H}$, Tu J P, Zhang C Q, et al. Net-structured NiO-C nanocomposite as Li-intercalation electrode material. Electrochem Commun, 2007, 9: 1180-1184

7 Li Y G, Tan B, Wu Y Y. Mesoporous $\mathrm{Co}_{3} \mathrm{O}_{4}$ nanowire arrays for lithium ion batteries with high capacity and rate capability. Nano Lett, 2008, 8: 265-270

8 Sharma Y, Sharma N, Rao G V S, et al. Nanophase $\mathrm{ZnCo}_{2} \mathrm{O}_{4}$ as a high performance anode material for Li-Ion batteries. Adv Funct Mater, 2007, 17: 2855-2861

9 Wu Z H, Ren W C, Wen L, et al. Graphene anchored with $\mathrm{Co}_{3} \mathrm{O}_{4}$ nanoparticles as anode of lithium ion batteries with enhanced reversible capacity and cyclic performance. ACS Nano, 2010, 4: 3187

10 Liang H Y, Raitano J M, Zhang L H, et al. Controlled synthesis of $\mathrm{Co}_{3} \mathrm{O}_{4}$ nanopolyhedrons and nanosheets at low temperature. Chem Commun, 2009, 7569-7571
11 Wang Q, Wen Z H., Li J H. Solvent-controlled synthesis and electrochemical lithium storage of one-dimensional $\mathrm{TiO}_{2}$ nanostructures. Inorg Chem, 2006, 45: 6944-6949

12 Tian L L, Zhuang Q C, Li J. Mechanism of intercalation and deintercalation of lithium ions in graphene nanosheets. Chin Sci Bull, 2011, 56: 3204-3212

13 Ding Y, Zhang P, Long Z, et al. Synthesis and electrochemical properties of $\mathrm{Co}_{3} \mathrm{O}_{4}$ nanofibers as anode materials for lithium-ion batteries. Mater Lett, 2008, 62: 3410-3412

14 Qiu Y, Yang S, Deng $\mathrm{H}$, et al. A novel nanostructured spinel $\mathrm{ZnCo}_{2} \mathrm{O}_{4}$ electrode material: Morphology conserved transformation from a hexagonal shaped nanodisk precursor and application in lithium ion batteries. J Mater Chem, 2010, 20: 4439-4444

$15 \mathrm{Li} \mathrm{Y} \mathrm{M}$, Marshall V Z, Chiang S, et al. $\mathrm{KOH}$ modified graphene nanosheets for supercapacitor electrode. J Power Sources, 2011, 196: 6003-6006

$16 \mathrm{Li} \mathrm{Y} \mathrm{M,} \mathrm{Lv} \mathrm{X} \mathrm{J,} \mathrm{Lu} \mathrm{J,} \mathrm{et} \mathrm{al.} \mathrm{Preparation} \mathrm{of} \mathrm{SnO}_{2}$-nanocrystal/graphenenanosheets composites and their lithium storage ability. J Phys Chem C, 2010, 114: 21770-21774

17 Zhai C, Du N, Zhang H, et al. Large-scale synthesis of ultrathin hexagonal tin disulfide nanosheets with highly reversible lithium storage. Chem Commun, 2011, 47: 1270-1272

$18 \mathrm{Li} \mathrm{Y} \mathrm{G}$, Hasin P, Wu Y Y. $\mathrm{Ni}_{x} \mathrm{Co}_{3-x} \mathrm{O}_{4}$ nanowire arrays for electrocatalytic oxygen evolution. Adv Mater, 2010, 22: 1926-1929

19 Kang Y M, Kim K T, Kim J H, et al. Electrochemical properties of $\mathrm{Co}_{3} \mathrm{O}_{4}, \mathrm{Ni}-\mathrm{Co}_{3} \mathrm{O}_{4}$ mixture and $\mathrm{Ni}-\mathrm{Co}_{3} \mathrm{O}_{4}$ composite as anode materials for $\mathrm{Li}$ ion secondary batteries. J Power Sources, 2004, 133: 252-259

20 Hu C C, Lee Y S, Wen T C. The physicochemical/electrochemical properties of binary Ni-Co oxides. Mater Chem Phys, 1997, 48: 246-254

21 Geim A K, Novoselov K S. The rise of graphene. Nat Mater, 2007, 6: $183-191$

22 Chen D, Tang L H, Li J H. Graphene-based materials in electrochemistry. Chem Soc Rev, 2010, 39: 3157-3180

Open Access This article is distributed under the terms of the Creative Commons Attribution License which permits any use, distribution, and reproduction in any medium, provided the original author(s) and source are credited. 